\title{
Sacrococcygeal Teratoma
}

National Cancer Institute

\section{Source}

National Cancer Institute. Sacrococcygeal Teratoma. NCI Thesaurus. Code C99055.

A teratoma that is found at the base of the coccyx. It is the most commonly seen tumor in newborns. 